\title{
Hypothetical Learning Trajectory (HLT) dalam Perspektif Psikologi Belajar Matematika
}

\author{
Raizal Rezky ${ }^{1} *$ \\ ${ }^{1}$ SMP Negeri 1 Sampolawa. Buton Selatan, Indonesia. \\ * Korespondensi Penulis. E-mail: raizalrezky.rr@gmail.com, Telp: +6285343940054
}

\section{Abstrak}

Matematika merupakan mata pelajaran yang dipelajari hampir ditiap jenjang pendidikan. Namun fakta yang terjadi di lapangan masih banyak siswa cenderung menganggap matematika sebagai pelajaran yang membosankan dan menakutkan karena penuh dengan angka dan rumus. Untuk itu pembelajaran matematika dilakukan dengan memperhatikan konsep akan menjadikan siswa belajar bermakna (meaningful learning). Konsep yang dipelajari disesuaikan dengan alur belajar yang dimiliki oleh siswa. Alur belajar atau hypothetical learning trajectory sendiri terdiri atas tiga aspek yaitu: (1) tujuan pembelajaran, (2) aktivitas belajar, (3) hipotesis belajar. Hipotesis belajar diperlukan guru guna mendesain pembelajaran yang akan sesuai dengan pola pemikiran siswa di kelas sesuai dengan karakteristik siswa.

Kata Kunci: hipotesis alur belajar, belajar bermakna

\section{Hypothetical Learning Trajectory (HLT) in Psychology Learning Mathematics Perspective}

\begin{abstract}
Mathematics was a subject that was studied in almost every level of education. But the facts that occur in the field are still many students tend to think of mathematics as a boring and scary lesson because it was full of numbers and formulas. For that mathematics learning was done by paying attention to the concept will make students learn meaningfully. The concepts learned were tailored to the learning flow that was owned by students. The learning flow or hypothetical learning trajectory itself consists of three aspects, i.e. (1) learning objectives, (2) learning activities, and (3) learning hypotheses. The learning hypothesis was needed by the teacher to design learning that would suit the thinking patterns of students in the class according to the characteristics of students.
\end{abstract}

Keywords: hypothetical learning trajectory, meaningful learning 


\section{PENDAHULUAN}

Matematika merupakan mata pelajaran yang dipelajari hampir ditiap jenjang pendidikan. ${ }^{1}$ Pentingnya matematika ini dapat dilihat dari tujuannya, menurut National Council of Teacher of Mathematics (NCTM) bahwa tujuan pembelajaran matematika agar siswa: (1) belajar menghargai matematika; (2) percaya diri dalam kemampuannya mengerjakan matematika; (3) menjadi problem solver matematika; (4) belajar untuk berkomunikasi secara matematika; (5) belajar untuk melakukan penalaran secara matematika. ${ }^{2}$

Dari tujuan yang dikemukakan oleh NCTM tersebut tersirat bahwa siswa dalam belajar berproses untuk menjadi tahu dari pengalaman yang telah mereka dapatkan dikehidupannya. ${ }^{3}$ Hal ini sesuai dengan apa yang dikemukakan oleh Driscoll menyatakan bahwa belajar adalah perubahan diri yang disebabkan oleh pengalaman. ${ }^{4}$ Namun fakta yang terjadi di lapangan masih banyak siswa cenderung menganggap matematika sebagai pelajaran yang membosankan dan menakutkan karena penuh dengan angka dan rumus. ${ }^{5}$

Sehingga diperlukan suatu proses pembelajaran yang perlu memperhatikan siswa dari bagaimana siswa tersebut berpikir tentang matematika itu sendiri yang nantinya siswa dapat menghubungkan antara materi satu dan lainnya. ${ }^{6}$ Sesuai dengan apa yang dikemukakan oleh Ausuble bahwa pembelajaran bermakna merupakan suatu proses pembelajaran yang secara aktif menghubungkan materi baru dengan pengetahuan siswa yang sudah ada sebelumnya. ${ }^{7}$

Untuk tujuan itu, menurut Clements, Gravemeijer, dan Simon kita perlu mengkonseptualisasikan lintasan pembelajaran sebagai deskripsi pemikiran dan pembelajaran anak-anak dalam domain matematis tertentu dan rute dugaan yang terkait melalui serangkaian tugas instruksional. ${ }^{8}$

Lintasan belajar atau hypothetical learning trajectory ( $H L T)$ menurut Clements, Gravemeijer, dan Simon merupakan cara untuk menjelaskan aspek penting pemikiran pedagogis yang terlibat dalam memahami pengajaran matematika. ${ }^{9}$ Secara khusus, ini menggambarkan bagaimana pendidik matematika (guru, peneliti, dan pengembang kurikulum) berorientasi pada perspektif konstruktivis dan tujuan pembelajaran matematika tertentu untuk siswa, dapat memikirkan perancangan dan penggunaan tugas matematika untuk mempromosikan pembelajaran matematika yang konseptual.

Pembelajaran matematika dilakukan dengan memperhatikan konsep akan menjadikan siswa belajar dengan bermakna. ${ }^{10}$ Walaupun menurut Skemp konsep-konsep matematika bersifat abstrak, yang saling berkorelasi membentuk konsep baru yang lebih kompleks. ${ }^{11}$ Akan tetapi pembelajaran

${ }^{1}$ K Kartianom and Heri Retnawati, "Why Are Their Mathematical Learning Achievements Different? ReAnalysis Timss 2015 Data in Indonesia, Japan And Turkey," International Journal on New Trends in Education \& Their Implications (IJONTE) 9, no. 2 (2018).

${ }^{2}$ NCTM, Principle and Standards for School Mathematics (Reston: Viginia, 2000).

${ }^{3}$ Kartianom Kartianom and Oscar Ndayizeye, "What's Wrong with the Asian and African Students' Mathematics Learning Achievement? The Multilevel PISA 2015 Data Analysis for Indonesia, Japan, and Algeria," Jurnal Riset Pendidikan Matematika 4, no. 2 (2017): 200-210.

${ }^{4}$ Robert E Slavin, Cooperative Learning: Theory, Research, Andpractice (London: Allyn and Bacon, 2006).

${ }^{5}$ L Leonard and Supardi US, "Pengaruh Konsep Diri, Sikap Siswa Pada Matematika, Dan Kecemasan Siswa Terhadap Hasil Belajar Matematika," Cakrawala Pendidikan, no. 3 (2010): 341-52.

${ }^{6}$ Heri Retnawati et al., "Teachers' Knowledge about Higher-Oeder Thinking Skills and Its Learning Strategy," Problems of Education in the 21st Century 76, no. 2 (2018).

${ }^{7}$ Richard E Mayer, The Promise of Educational Psychology: Learning in The Content Areas, vol. 1 (NJ: Prentice Hall, 1999).

${ }^{8}$ Douglas H Clements and Julie Sarama, "Learning Trajectories in Mathematics Education," Mathematical Thinking and Learning 6, no. 2 (2004): 81-89.

${ }^{9}$ Martin A Simon and Ron Tzur, "Explicating the Role of Mathematical Tasks in Conceptual Learning: An Elaboration of the Hypothetical Learning Trajectory," Mathematical Thinking and Learning 6, no. 2 (2004): 91-104.

${ }^{10}$ Kartianom Kartianom, “Diagnosis Kesalahan Konsep Materi Matematika SMP Berdasarkan Hasil Ujian Nasional Di Kota Baubau.” (UNY, 2017).

${ }^{11}$ Richard R Skemp, The Psychology of Learning Mathematics: Expanded American Edition (Routledge, 2012). 
memahami konsep itu menjadi sangat penting, karena dari sebuah konsep yang dipahami dengan bermakna oleh siswa akan menjadikan siswa mampu membedakan antara satu dengan yang lainnya. ${ }^{12}$

Untuk mencapai pembelajaran bermakna oleh siswa itu sangat erat kaitannya dengan proses belajar yang dilalui. Dengan memahami proses atau lintasan belajar siswa, guru dapat menemukan beberapa hal yang perlu diperhatikan agar siswa dapat mengkonstruksi pengetahuan secara efektif yang menghasilkan pembelajaran bermakna.

\section{METODE}

Metode penelitian yang dilakukan penulis merupakan kajian literatur, yaitu penelitian yang dilakukan hanya berdasarkan karya tulis, seperti buku, jurnal, dan referensi lainnya. Penulis mengumpulkan referensi yang relevan yang berkaitan dengan tema hypothetical learning trajectory $(H L T)$ dalam perspektif psikologi.

\section{PEMBAHASAN}

\section{Hypothetical Learning Trajectory}

Istilah hypothetical learning trajectory (HLT) sendiri pertama kali dikemukakan dan digunakan oleh Simon menyatakan bahwa "alur belajar hipotetik adalah dugaan seorang desainer atau seorang peneliti mengenai kemungkinan belajar yang terjadi pada saat merancang" yang mana dalam HLT ini menurut Simon, "a hypothetical learning trajectory included the learning goal, the learning activities, and the thinking in which the students might engage". ${ }^{13}$ Maksudnya yaitu alur belajar atau HLT mencakup tiga aspek yang berupa tujuan pembelajaran, aktivitas pembelajaran, dan dugaan pemikiran saat siswa terlibat dalam pembelajaran.

Bakker (2004) mengungkapkan bahwa "The HLT is the link between an instruction theory and concrete teaching experiment ". ${ }^{14}$ Maksudnya yaitu $H L T$ merupakan penghubung antara teori dan proses perlakuan pembelajaran di dalam kelas. Sejalan dengan hal itu, Wijaya (2009) mengungkapkan bahwa pentingnya $H L T$ bisa dianalogikan dengan rute perjalanan. Jika kita memahami rute-rute yang mungkin untuk menuju tujuan kita maka kita bisa memilih rute yang baik. ${ }^{15}$

Dari HLT yang telah diujikan akan diperoleh learning trajectory yang dapat digunakan. Pengertian learning trajectory disampaikan pula oleh Clements dan Sarama (2004) bahwa gambaran dari cara berpikir dan belajar siswa terhadap suatu materi matematika, dan suatu perkiraan yang terhubung (dengan cara berpikir dan belajar siswa) melalui suatu kumpulan tugas pembelajaran yang dirancang (oleh guru) untuk proses mental atau kegiatan yang diperkirakan dapat menggerakan siswa meniti kemajuan perkembangannya (development progression) terhadap suatu materi matematika yang dipelajari. ${ }^{16}$

Komponen-komponen $H L T$ yang dikemukakan para ahli di atas dapat tergambar dengan jelas pada Gambar 1 seperti yang dikemukakan oleh Simon bahwa HLT dalam pembelajaran matematika terbagi tiga bagian. ${ }^{17}$

Bagian pertama teacher's learning goals (tujuan guru mengajar) yang dipengaruhi dua faktor yaitu (1) teacher's knowledge of mathematics (pemahaman guru tentang matematika). Pentingnya pemahaman guru dikarenakan guru harus mengetahui urutan dari alur belajar matematika yang bersifat

12 Kartianom Kartianom and Djemari Mardapi, "The Utilization of Junior High School Mathematics National Examination Data: Conceptual Error Diagnosis," REiD (Research and Evaluation in Education) 3, no. 2 (2018).

${ }^{13}$ Clements and Sarama, "Learning Trajectories in Mathematics Education."

14 Arthur Bakker, Design Research in Statistics Education: On Symbolizing and Computer Tools (Amersfoort: Wilco Press, 2004).

15 A Wijaya, "Hypothetical Learning Trajectory Dan Peningkatan Pemahaman Konsep Pengukuran Panjang [Hypothetical Learning Trajectory and Improvement of Length Measurement Concept]," in Seminar Nasional Matematika. Yogyakarta, 2009.

${ }^{16}$ Clements and Sarama, "Learning Trajectories in Mathematics Education."

17 Julie Amador and Teruni Lamberg, "Learning Trajectories, Lesson Planning, Affordances, and Constraints in the Design and Enactment of Mathematics Teaching," Mathematical Thinking and Learning 15, no. 2 (2013): 146-70. 
kontinu dan (2) teacher's hypothesis of students' knowledge (dugaan guru tentang pengetahuan siswa). Guru juga harus mengetahui sejauh mana siswa paham terhadap pembelajaran yang diajarkan, agar proses pengajaran di kelas berlangsung secara maksimal.

Bagian kedua teacher's plan for learning activities dipengaruhi empat faktor yaitu (1) teacher's knowledge of mathematics, (2) teacher's knowledge of mathematical activities and representations, (3) teacher's hypothesis of students' knowledge, dan (4) teacher's theories about mathematics learning and teaching.

Bagian ketiga teacher's hypothesis of learning process dipengaruhi oleh tiga faktor yaitu (1) teacher's knowledge of mathematics, (2) teacher's hypothesis of students' knowledge, dan (3) teacher's knowledge of student learning of particular content.

Ketiga bagian $H L T$ tersebut merupakan aspek yang menjadi penilaian dari pemahaman siswa. Sehingga pemahaman siswa diajarkan bukan hanya didapatkan dari hasil menjawab soal akan tetapi di nilai dari kesemua aspek yang dipaparkan di atas.

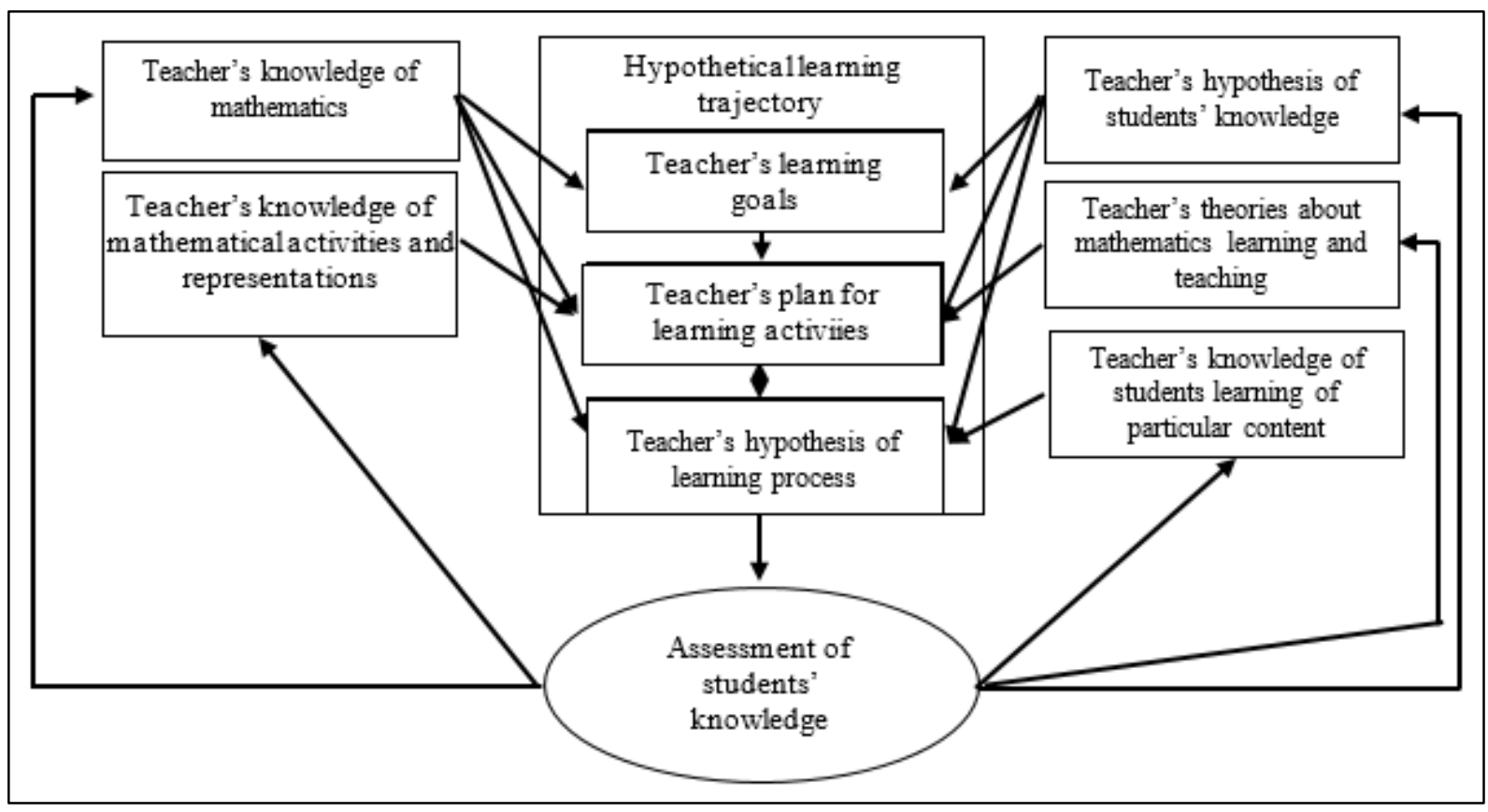

Gambar 1. Hypothetical learning trajectory dalam Pembelajaran Matematika oleh Simon

Sebagaimana pendekatan-pendekatan yang lain, learning trajectory mempunyai beberapa kelebihan dan kelemahan. Beberapa manfaat learning trajectory dapat dilihat pada Tabel 1.

Tabel 1. Manfaat Learning Trajectory

Wilson, Sztajn, dan Confrey (2013)

\section{Manfaat}

Learning trajectory memandu guru untuk membuat keputusan pembelajaran.

"Early accounts suggest that teachers" knowledge of an LT improved their own mathematics content knowledge" (Mojica, 2010), "guided their instructional decisions" (Wilson, 2009), and "enhanced their abilities to use student thinking" (Clements, Sarama, Spitler, Lange, \& Wolfe, 2011). ${ }^{18}$

18 Wilson P Holt, Sztajn Paola, and Edgington Cyndi, "Designing Professional Learning Tasks for Mathematics Learning Trajectories," PNA 7, no. 4 (2013): 135-43. 


\begin{tabular}{|c|c|}
\hline Menurut & Manfaat \\
\hline $\begin{array}{c}\text { Clements \& Sarama (2004) } \\
\text { Empson (2011) }\end{array}$ & $\begin{array}{l}\text { Learning trajectory memberikan } \\
\text { gambaran } \\
\text { pertimbangan dan komponen-komponen teoritik }\end{array}$ \\
\hline Amador \& Lamberg (2013) & $\begin{array}{l}\text { kepada guru untuk membuat perencanaan, }{ }^{19} \\
\text { pembentukan konsep, }{ }^{20} \text { dan } \\
\text { pembelajaran. } .^{21}\end{array}$ \\
\hline Wilson, Mojica \& Confrey (2013) & $\begin{array}{l}\text { Dengan mempelajari learning trajectory, guru } \\
\text { dapat menggunakan proses ini membuat model } \\
\text { tentang cara berpikir siswa. } \\
\text { "by learning about a LT, teacher may use these } \\
\text { processes in different ways to build models of } \\
\text { students thinking". }{ }^{22}\end{array}$ \\
\hline Sarama (2009) & $\begin{array}{l}\text { Development progression menggambarkan alur } \\
\text { belajar siswa dalam belajar. } \\
\text { "The second part of learning trajectory consists } \\
\text { of levels of thinking, each more sophisticated } \\
\text { than the last, that lead to achieving the } \\
\text { mathematical goal. That is, the developmental } \\
\text { progression describes a typical path children } \\
\text { follow in developing understanding and skill } \\
\text { about that mathematical topic". }{ }^{23}\end{array}$ \\
\hline
\end{tabular}

Beberapa point di atas merupakan manfaat dari learning trajectory. Adapun kelemahan learning trajectory adalah sebagai berikut: (1) learning trajectory setiap siswa berbeda, maka menggunakan learning trajectory dalam pembelajaran bisa menjadi sangat rumit, ${ }^{24}$ dan (2) learning trajectory hanya terbatas pada apa yang dapat dan tidak dapat ditentukan dalam belajar matematika setiap saat, lebih khusus mungkin tidak bias di aplikasikan untuk beberapa materi tertentu. Hal ini sesuai dengan apa yang disampaikan oleh Empson (2011) bahwa "learning trajectory may be limited in what they can and cannot specify in terms of learning mathematics over time; and in particular, they may not be applicable to certain critical aspects of the mathematics curriculum". ${ }^{25}$

\section{Belajar Bermakna (Meaningful Learning) Ausubel}

David Ausubel adalah seorang ahli psikologi pendidikan yang terkenal dengan teori belajar bermakna (meaningfull). Ausubel membedakan antara belajar menemukan dengan belajar menerima. Pada belajar menerima siswa hanya menerima, jadi tinggal menghafalkannya, tetapi pada belajar menemukan konsep ditemukan oleh siswa, jadi tidak menerima pelajaran begitu saja. ${ }^{26}$ Menurut Ausubel pembelajaran bermakna merupakan suatu proses mengaitkan informasi baru pada konsepkonsep relevan yang terdapat dalam struktur kognitif seseorang. ${ }^{27}$ Struktur kognitif meliputi fakta-fakta, konsep-konsep, dan generalisasi-generalisasi yang telah dipelajari dan diingat siswa.

\footnotetext{
${ }^{19}$ Clements and Sarama, "Learning Trajectories in Mathematics Education."

${ }^{20}$ Susan B Empson, "On the Idea of Learning Trajectories: Promises and Pitfalls," The Mathematics Enthusiast 8, no. 3 (2011): 571-96.

${ }^{21}$ Amador and Lamberg, "Learning Trajectories, Lesson Planning, Affordances, and Constraints in the Design and Enactment of Mathematics Teaching."

${ }^{22}$ P Holt Wilson, Gemma F Mojica, and Jere Confrey, "Learning Trajectories in Teacher Education: Supporting Teachers' Understandings of Students' Mathematical Thinking," The Journal of Mathematical Behavior 32, no. 2 (2013): 103-21.

${ }^{23}$ Douglas H Clements and Julie Sarama, Learning and Teaching Early Math: The Learning Trajectories Approach (Routledge, 2014).

${ }^{24}$ Empson, "On the Idea of Learning Trajectories: Promises and Pitfalls."

${ }^{25}$ Empson.

${ }^{26}$ Baharuddin Baharuddin and Esa Nur Wahyuni, "Teori Belajar Dan Pembelajaran” (Ar-Ruzz Media, 2008).

${ }^{27}$ Baharuddin and Wahyuni.
} 
Faktor-faktor utama yang mempengaruhi belajar bermakna menurut Ausubel adalah struktur kognitif yang ada, stabilitas dan kejelasan pengetahuan dalam suatu bidang studi tertentu dan pada waktu tertentu. Pembelajaran bermakna terjadi apabila seseorang belajar dengan mengasosiasikan fenomena baru ke dalam struktur pengetahuan mereka. Dalam proses belajar seseorang mengkonstruksi apa yang telah ia pelajari dan mengasosiasikan pengalaman, fenomena, dan fakta-fakta baru ke dalam struktur pengetahuan mereka.

Ada beberapa tipe belajar menurut Ausubel yaitu: (1) belajar dengan penemuan yang bermakna yaitu mengaitkan pengetahuan yang telah dimilikinya dengan materi pelajaran yang dipelajari itu. Atau sebaliknya, siswa terlebih dahulu menemukan pengetahuannya dari apa yang ia pelajari kemudian pengetahuan baru tersebut ia kaitkan dengan pengetahuan yang sudah ada; (2) belajar dengan penemuan yang tidak bermakna yaitu pelajaran yang dipelajari ditemukan sendiri oleh siswa tanpa mengaitkan pengetahuan yang telah dimilikinya, kemudian dia hafalkan; dan (3) belajar menerima (ekspositori) yang bermakna yaitu materi pelajaran yang telah tersusun secara logis disampaikan kepada siswa sampai bentuk akhir, kemudian pengetahuan yang baru ia peroleh itu dikaitkan dengan pengetahuan lain yang telah dimiliki. ${ }^{28}$

Prasyarat agar belajar menerima menjadi bermakna menurut Ausubel yaitu: (1) siswa memiliki strategi yang bermakna; (2) tugas-tugas belajar yang diberikan kepada siswa harus sesuai dengan pengetahuan yang telah dimiliki oleh siswa; dan (3) tugas-tugas belajar yang diberikan harus sesuai dengan tahap perkembangan intelektual siswa. ${ }^{29}$

\section{Hypothetical Learning Trajectory untuk Mencapai Meaningful Learning}

Hypothetical learning trajectory (HLT) yang didalamnya memuat serangkaian tugas instruksional agar dapat memahamkan siswa terhadap konsep pembelajaran matematika merupakan salah satu aspek penting yang harus dimiliki oleh guru dalam mengajarkan siswa belajar bermakna (meaningful learning). Ini dikarenakan dalam $H L T$ itu sangat mempertimbangkan pengetahuan yang dimiliki oleh siswa.

$H L T$ sendiri menciptakan suatu hipotesis atau dugaan guru tentang bagaimana siswa belajar sehingga guru tidak hanya mempertimbangkan materi yang ada tetapi juga melihat bagaimana siswa tersebut apakah sudah memahaminya atau belum. sehingga dalam proses pembelajaran untuk mencapai siswa yang belajar bermakna diperlukan desain-desain pembelajaran yang disesuaikan dengan karakteristik siswa.

Dugaan yang dilakukan guru tersebut dapat dicermati dengan sejauh mana siswa memahami materi prasyarat terhadap suatu materi yang diajarkan ataupun dari pengalaman guru itu sendiri, sehingga dari hal tersebut guru dapat mengkomunikasikan dengan siswa mengenai alur pembelajaran yang akan di laksanakn di kelas tersebut. Dugaan yang coba di lakukan guru dapat di lihat pada Gambar $2 .^{30}$

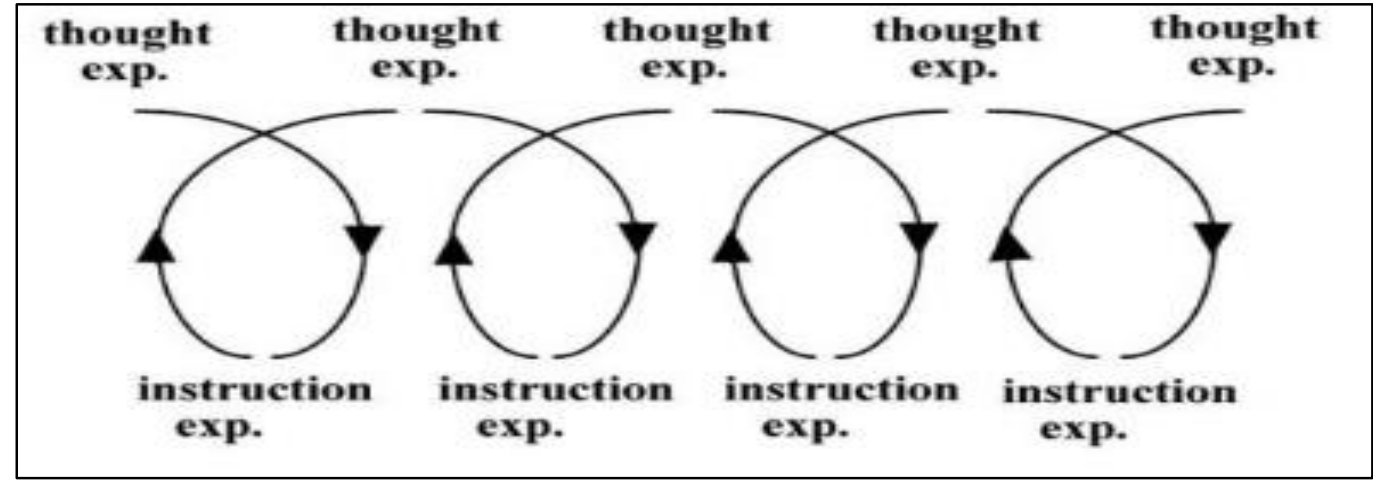

Gambar 2. Proses Interaktif antara Teori dan Percobaan

${ }^{28}$ N Rahma, "Belajar Bermakna Ausubel,” Al-Khawarizmi 1, no. 1 (2013): 43-48.

${ }^{29}$ Rahma.

${ }^{30}$ R Rezky and A Wijaya, "Designing Hypothetical Learning Trajectory Based on van Hiele Theory: A Case of Geometry," in Journal of Physics: Conference Series, vol. 1097 (IOP Publishing, 2018), 12129. 


\section{SIMPULAN}

Proses belajar yang dilalui oleh siswa menjadikan siswa belajar memahami untuk menghasilkan proses belajar bermakna sangatlah erat kaitannya dengan dugaan atau hipotesis pembelajaran yang dilakukan oleh guru. Karena dari proses guru menduga bagaimana alur belajar siswa maka dalam pembelajarannya guru akan menyesuaikan dengan karakteristik siswa di kelas tersebut.

\section{DAFTAR PUSTAKA}

Amador, Julie, and Teruni Lamberg. "Learning Trajectories, Lesson Planning, Affordances, and Constraints in the Design and Enactment of Mathematics Teaching." Mathematical Thinking and Learning 15, no. 2 (2013): 146-70.

Baharuddin, Baharuddin, and Esa Nur Wahyuni. "Teori Belajar Dan Pembelajaran.” Ar-Ruzz Media, 2008.

Bakker, Arthur. Design Research in Statistics Education: On Symbolizing and Computer Tools. Amersfoort: Wilco Press, 2004.

Clements, Douglas H, and Julie Sarama. Learning and Teaching Early Math: The Learning Trajectories Approach. Routledge, 2014.

- "Learning Trajectories in Mathematics Education." Mathematical Thinking and Learning 6, no. 2 (2004): 81-89.

Empson, Susan B. "On the Idea of Learning Trajectories: Promises and Pitfalls." The Mathematics Enthusiast 8, no. 3 (2011): 571-96.

Kartianom, K, and Heri Retnawati. "Why Are Their Mathematical Learning Achievements Different? Re-Analysis Timss 2015 Data in Indonesia, Japan And Turkey." International Journal on New Trends in Education \& Their Implications (IJONTE) 9, no. 2 (2018).

Kartianom, Kartianom. "Diagnosis Kesalahan Konsep Materi Matematika SMP Berdasarkan Hasil Ujian Nasional Di Kota Baubau." UNY, 2017.

Kartianom, Kartianom, and Djemari Mardapi. "The Utilization of Junior High School Mathematics National Examination Data: Conceptual Error Diagnosis." REiD (Research and Evaluation in Education) 3, no. 2 (2018).

Kartianom, Kartianom, and Oscar Ndayizeye. "What's Wrong with the Asian and African Students' Mathematics Learning Achievement? The Multilevel PISA 2015 Data Analysis for Indonesia, Japan, and Algeria." Jurnal Riset Pendidikan Matematika 4, no. 2 (2017): 200-210.

Leonard, L, and Supardi US. "Pengaruh Konsep Diri, Sikap Siswa Pada Matematika, Dan Kecemasan Siswa Terhadap Hasil Belajar Matematika." Cakrawala Pendidikan, no. 3 (2010): 341-52.

Mayer, Richard E. The Promise of Educational Psychology: Learning in The Content Areas. Vol. 1. NJ: Prentice Hall, 1999.

NCTM. Principle and Standards for School Mathematics. Reston: Viginia, 2000.

P Holt, Wilson, Sztajn Paola, and Edgington Cyndi. "Designing Professional Learning Tasks for Mathematics Learning Trajectories." PNA 7, no. 4 (2013): 135-43.

Rahma, N. "Belajar Bermakna Ausubel." Al-Khawarizmi 1, no. 1 (2013): 43-48.

Retnawati, Heri, Hasan Djidu, Ezi Apino, Kartianom Kartianom, and Risqa D Anazifa. "Teachers' Knowledge about Higher-Oeder Thinking Skills and Its Learning Strategy." Problems of Education in the 21st Century 76, no. 2 (2018).

Rezky, R, and A Wijaya. "Designing Hypothetical Learning Trajectory Based on van Hiele Theory: A Case of Geometry." In Journal of Physics: Conference Series, 1097:12129. IOP Publishing, 2018.

Simon, Martin A, and Ron Tzur. "Explicating the Role of Mathematical Tasks in Conceptual Learning: An Elaboration of the Hypothetical Learning Trajectory." Mathematical Thinking and Learning 6, no. 2 (2004): 91-104.

Skemp, Richard R. The Psychology of Learning Mathematics: Expanded American Edition. Routledge, 2012.

Slavin, Robert E. Cooperative Learning: Theory, Research, Andpractice. London: Allyn and Bacon, 2006.

Wijaya, A. "Hypothetical Learning Trajectory Dan Peningkatan Pemahaman Konsep Pengukuran Panjang [Hypothetical Learning Trajectory and Improvement of Length Measurement Concept]." In Seminar Nasional Matematika. Yogyakarta, 2009. 
EKSPOSE: Jurnal Penelitian Hukum dan Pendidikan, 18 (1), June 2019 - 769

Raizal Rezky

Wilson, P Holt, Gemma F Mojica, and Jere Confrey. "Learning Trajectories in Teacher Education: Supporting Teachers' Understandings of Students' Mathematical Thinking." The Journal of Mathematical Behavior 32, no. 2 (2013): 103-21. 